\title{
Processos de trabalho e criação no Murundum - Grupo de Dança Contemporânea da UFSJ
}

\author{
Working and creative processes at Murundum - Contemporary Dance Group of \\ UFSJ
}

\author{
Juliana Reis Monteiro dos Santos', Giselle Mara Raimundo² \\ 1 Professora. Universidade Federal de São João del Rei (UFSJ), Brasil. E-mail: jrms@ufsj.edu.br \\ 2 Bolsista de extensão. Universidade Federal de São João del Rei (UFSJ), Brasil. E-mail: gisellemaramg@gmail.com
}

Recebido em: 26/03/2015 | Aprovado em: 24/06/2015

DOI: 10.12957/interag.2016.15689

\section{Resumo}

Este relato refere-se à minha experiência como bolsista/integrante no Projeto de Extensão Murundum - Grupo de Dança Contemporânea da UFSJ, informando as atividades do grupo realizadas ao longo de 2014. Os principais objetivos do trabalho nesse período foram: ampliar a percepção de seus integrantes e sua possibilidade de resposta frente a estímulos variados, bem como proporcionar-lhes a descoberta de movimentos próprios a partir dos quais foi gerada uma cena coletiva, chamada Rizoma, levada a público posteriormente. Para pautar suas ações e criações, como metodologia de trabalho o grupo adotou as pesquisas do Movère (subnúcleo do GTRANS da universidade, do qual faço parte), que confluem com o processo de Busca e Retomada, defendido por Adilson Siqueria, bem como com alguns princípios do Contato Improvisação.

Tal escolha, tanto contribuiu com a preservação das especificidades e características de cada participante, como estimulou o aspecto autoral do trabalho desenvolvido.

Palavras-chave: Processo criativo de grupo, Dança contemporânea, Sistematização de trabalho.

Área temática: Cultura (Linguística, Letras e Artes). Linha de extensão: Artes Cênicas.

\begin{abstract}
This report refers to my experience as a research fellow and member of Murundum - Contemporary Dance Group of UFSJ, a Community Project, and informs of the activities carried out in 2014. The main objectives of the Project during this year were: to expand the perception of the members and their ability to respond to different stimuli as well as to help them discover their own movements, from which a collective scene named Rizoma was generated and acted out later To base their actions and creations, the group adopted the Movère surveys (subnucleus of the GTRANS university, to which I belong) as work methodology. These arise in the process of Search and Resume defended by Adilson Siqueria, as well as some principles of Contact Improvisation.

This choice both contributed to the preservation of the specific features and characteristics of each participant and stimulated the authorial aspect of their work.
\end{abstract}

Keywords: Collective creative process, Contemporary dance, Systematization of work.

O projeto de extensão Grupo de Dança Contemporânea da UFSJ, criado em 2013, partiu do objetivo de buscar e estimular corpos dançantes; não apenas vinculados à Universidade, mas também oriundos das comunidades do Campo das Vertentes, com ou sem experiência prévia em dança, e de proporcionar aos participantes a 
experimentação teórico- prática em dança contemporânea e a exploração de movimentos que pudesse resultar numa cena espetacular.

Na edição de 2014 do projeto, estava prevista a consolidação de um grupo, constituído de um corpo estável, formado pelos participantes ingressos no ano anterior (chamado de G1) e pelos ingressos no ano corrente (G2), num processo de retroalimentação.

Com base na experiência do ano anterior, a principal diretriz do processo desse ano seria o estudo do movimento, o treinamento e o aprofundamento de questões técnicas, passando por elementos de propriocepção, bem como por procedimentos de composição e pela verticalização do estado de percepção/atenção e de presença/concentração dos participantes. Segundo Eleonora Fabião ${ }^{1}$, este é um estado em que se está "cuidadosamente atento a si, ao outro, ao meio" e que permite que "o macro e o mínimo, grandezas que geralmente escapam na lida quotidiana, possam ser adentradas e exploradas”. Buscava-se, também, nossa abertura ao jogo, à improvisação e aos impulsos corporais geradores de movimento, focando a interação e a criação coletiva.

Assim, no dia 29 de agosto de 2014, estreou o primeiro trabalho do grupo, já nomeado Murundum. Meu envolvimento com o projeto não só me aproximou da dança, como, mediante a possibilidade de apresentar a cena espetacular, reforçou meu interesse em fazer parte do mesmo.

Chamado Rizoma, o espetáculo foi realizado pelo G1 e apresentado até o dia 7 de setembro de 2014 no Centro Cultural da UFSJ (Solar da Baronesa) em São João Del Rei. Dirigido pelo então coordenador do projeto, o professor Adilson Siqueira, seu processo de criação baseou-se no conceito homônimo da teoria filosófica de Gilles Deleuze e Félix Guattari ${ }^{2}$, para quem o rizoma é um modelo descritivo ou epistemológico, "extraído" da estrutura de algumas plantas, cujos brotos podem se ramificar em qualquer ponto, ou engrossar e transformar-se em um bulbo ou tubérculo.

Deste modo, o espetáculo foi todo construído por ideias e estímulos surgidos de pontos diversos: das impressões de cada dançarino sobre a obra de artistas visuais, de sua própria experiência, das frases de movimentos geradas individualmente e que, depois de entrelaçadas, passavam a constituir o que seria dançado por todos. Regido pela imagem da "fragmentação" e "várias entradas" e pelo fato de que deveria ser visto de 
diversos ângulos pelo espectador, tanto a coreografia começava de pontos distintos a cada dia de apresentação, como o público tinha liberdade para passear pelo espaço da cena, precisando voltar outros dias, caso tivesse interesse em ter uma noção do todo.

Por se tratar de um local que abriga exposições de artes plásticas, o cenário projetado para o Centro Cultural partiu da ideia de instalação, construída com materiais de ferrovelho, permanecendo aberta à visitação do público nos dias em que o espetáculo não foi apresentado. O intuito das cenógrafas Ana Clara Furtado e Anna Paula Alves era que os materiais ali colocados fizessem referência à sociedade de consumo, que apresentassem vários caminhos por onde o público pudesse se deslocar e que, se visto de cima, se assemelhasse ao corte de um formigueiro na horizontal.

As músicas, com melodias variadas, propunham outro tipo de "entrada", fosse para o baião, o tango, entre outras. Também compunham a dramaturgia do espetáculo as projeções na parede do Solar das sombras dos bailarinos e de imagens em vídeo com partes do processo de trabalho e criação do grupo.

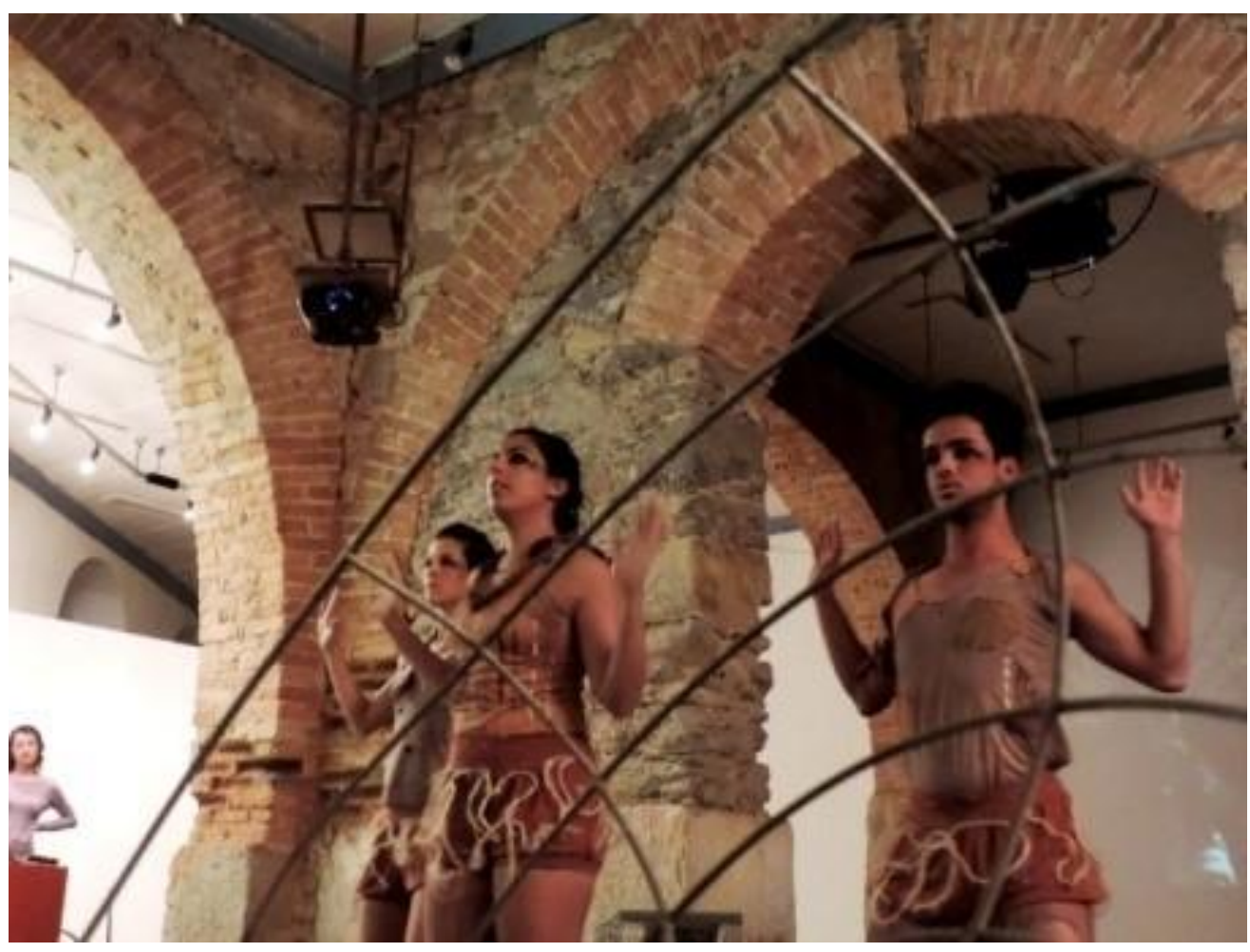

Figura 1. Acervo do grupo. Ensaio: Rizoma. Dançarinos: Giselle Mara, Camila Ribeiro e Júnio de Carvalho. 


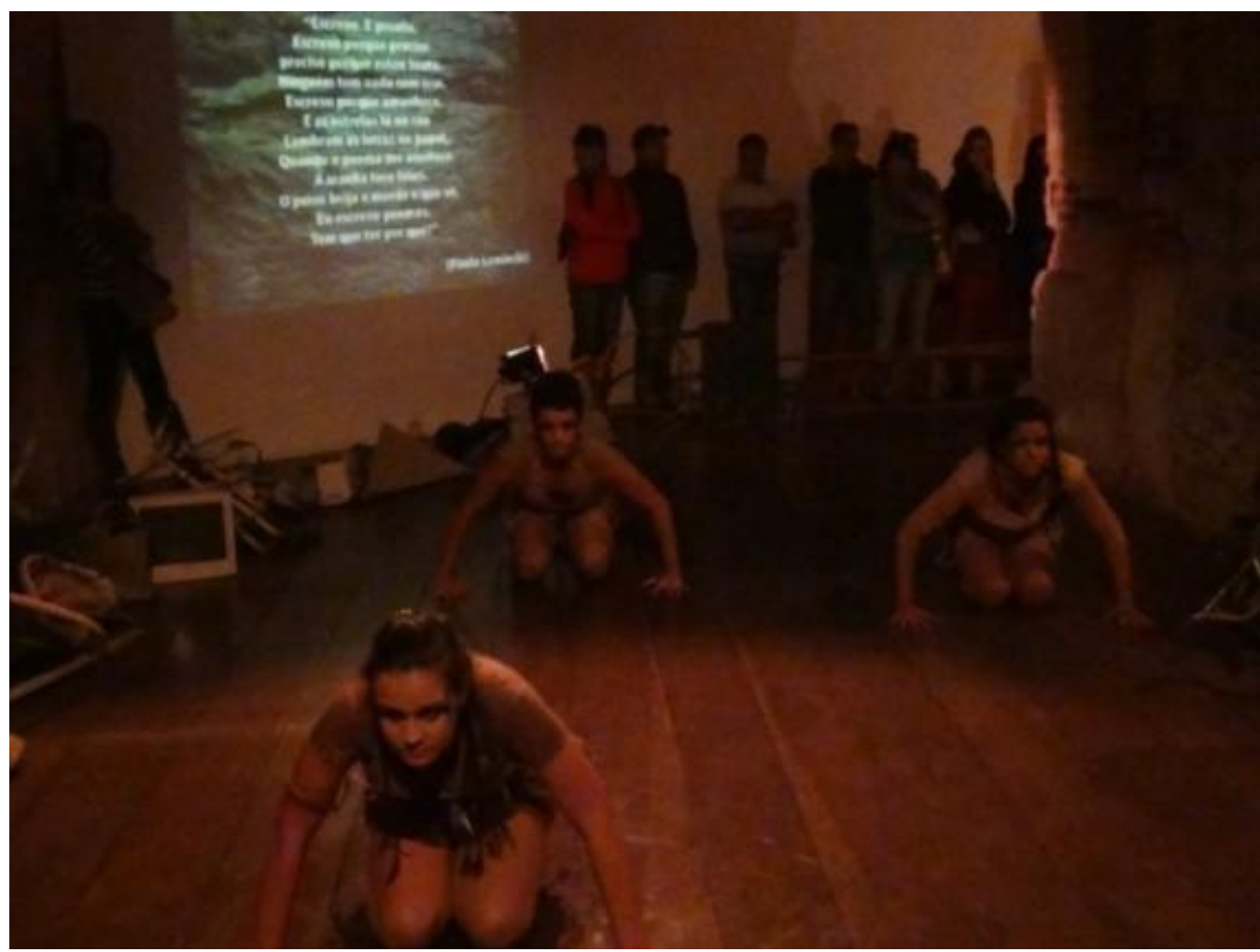

Figura 2. Acervo do grupo. Apresentação: Rizoma. Dançarinos: Bruna Capanema, Júnio de Carvalho e Ingrind Medina.

Para mim, ficou clara a ponte estabelecida entre a criação deste espetáculo e a metodologia de trabalho desenvolvida pelo Movère, do qual faço parte. Este é outro foco do Murundum: tomar por base as pesquisas do Movère, confluindo com o processo de busca e retomada ${ }^{3}$ para pautar suas ações e criações. Um dos subgrupos do Grupo Transdisciplinar de Pesquisa em Artes, Culturas e Sustentabilidade, o Movère se dedica ao estudo do corpo em situação de representação, à corporeidade, às técnicas do ator-dançarino, à cena e à Performance, objetivando desenvolver poéticas cênicas, técnicas e dramaturgias corporais, a fim de criar uma nova ecopoética para o trabalho do ator-dançarino.

A respeito do retorno do público à cena espetacular, houve críticas positivas e negativas. Ao final das apresentações, de modo informal, o elenco conversou com quem teve interesse em saber a respeito da construção de Rizoma. As impressões coletadas eram levadas ao ensaio do dia seguinte e, assim, de uma apresentação para outra, procurávamos reelaborar uma ou outra questão que nos tivesse sido apontada. Dos 
pontos negativos, cito: a plateia sentiu falta de um olhar direto dos bailarinos em direção a ela. A sensação era a de que "olhávamos sem estar olhando".

Lembrando que o olhar e o sentimento fazem parte da ação, reflito que os bailarinos do G1, que eram atores em sua maioria, se esqueceram de um dos pontos básicos: a interpretação.

Com as apresentações de Rizoma, entrei em contato com outro significado do que seja dançar. Mesmo que eu não fosse vista por todos da plateia, pois o próprio cenário não permitia, a cada apresentação eu descobria que meus movimentos, que são únicos, tocavam a atenção de alguém ali, ainda que por um mísero segundo. Com isso, pude perceber que estava sendo observada e analisada; me comoveu saber que um corpo sem formação profissional em dança possui todo o direito de se expressar e que a dança também pode brincar a favor ou contra a melodia tocada e continuar a sensibilizar quem a vê (idéia que foi trazida para os ensaios do grupo pela professora Juliana Monteiro, de seus estudos e treinamento em Viewpoints com a diretora estadunidense Anne Borgart) ${ }^{4}$.

Concluo que os riscos assumidos valeram a pena, como, por exemplo, mostrar o que foi desenvolvido em oito meses de trabalho ainda que com uma técnica de dança a ser apurada. Retomando as conversas informais travadas com a plateia, soubemos que o espetáculo apresentou uma proposta estética nova para a cidade de São João Del Rei, tendo tido boa repercussão. A maior parte do público compreendeu nossa intenção, o tema central do espetáculo e a heterogeneidade de seus participantes - nem todos eram bailarinos e alguns se apresentaram pela primeira vez.

Além dos professores Adilson Siqueira e Juliana Monteiro, toda esta etapa do trabalho contou com a colaboração da técnica em Lazer e Desenvolvimento Social do Departamento das Ciências da Educação Física e Saúde da UFSJ, Telma Freitas.

Finalizada a temporada do espetáculo, apenas três dos integrantes do Edital 2013 continuaram e, a partir da segunda quinzena de setembro, tive o primeiro contato com os novos participantes, o G2. Confesso minha satisfação ao ver a produção dos calouros dançantes e a energia de um grupo unido e nivelado, uma vez que nenhum deles vinha da dança e, assim como no Rizoma, essa era sua primeira experiência cênica. Todos 
estavam curiosos, entusiasmados e interessados com a possibilidade de produzir algo que fosse movido pela vontade de dançar.

Desta forma, o grupo foi convidado a realizar uma apresentação no campus Dom Bosco/UFSJ, na abertura do XII Congresso de Produção Científica e Acadêmica e da XII Semana de Extensão Universitária - SEMEX. Com isso, uma nova etapa de ensaios foi iniciada, para o que foi chamado de Intervenção \# 3: um trabalho voltado para a relação com o outro, para a percepção rítmica e espacial, que reuniu as vivências experimentadas pelo grupo até então, sob a batuta dos colaboradores: André Magela, Carolina de Pinho, Juliana Monteiro e Marcos Filho. E, como o próprio nome sugere, a intervenção não era um exercício fechado, mas a apresentação de fragmentos de um processo em andamento.

Passarei, agora, a relatar minha experiência com os colaboradores supracitados.

O professor Marcos Filho, do curso de Música da universidade desenvolveu exercícios de musicalização com o grupo, com o objetivo de trabalhar os parâmetros do som, a forma, jogos rítmicos, a apreciação musical e a análise auditiva. Os encontros seguiram uma dinâmica pré-estabelecida em quatro etapas: 1) exercícios rítmicos de aquecimento; 2) atividades de percepção sonora e improvisação; 3) atividades de escuta e análise; e 4) correspondência corporal da análise auditiva realizada na etapa anterior. Os exercícios de ritmo, pulso e som se basearam nas propostas de J. Dalcroze, Carl Orff e Ernani Maleta. Já a apreciação musical passou por obras como as Cirandinhas de Heitor Villa-Lobos, Carnaval dos Animais de E. Saint-Saens e obras modernas como as Bagatelas para Quarteto de Cordas de A. Webern e a Suite para Piano de A. Schoenberg. ${ }^{5}$

Isso nos proporcionou concentração, percepção sonora e sua ampliação na sala e a descoberta de sons emitidos pelo corpo. Como o professor coloca no relato acima, também vivenciamos, apenas por meio de movimentos, a interpretação de músicas instrumentais.

Sobre a colaboração do professor Magela, seu trabalho focou "a construção de uma pequena sequência individual de movimentos, com repetição precisa e o aprofundamento do movimento estruturado, o desenvolvimento e a ampliação das 
inteligências corporais junto aos participantes" e a "influência de sons e músicas na pesquisa de criação de movimento e a construção de trabalhos em dupla com movimentos fixados". 6

Três exercícios trazidos por ele complementaram bastante meu dia a dia com a dança, ao me proporcionarem outras dinâmicas de movimento. No primeiro, a indicação era para que imaginássemos nossos corpos ocos, com uma bolinha dentro a se locomover conforme nos movimentássemos. Lembro-me de experimentar o dançar conforme a melodia que essa figura imaginária produzia dentro de mim.

O segundo exercício foi um trabalho de atenção e precisão, desenvolvido a partir do contato com vários tipos de tecidos. Arremessados para o alto, cada participante deveria pegar apenas um e dar prosseguimento ao movimento vindo dele, sem quebrar seu fluxo. A partir desses elementos, busquei formas de desenvolver e ampliar minha consciência corporal fora da universidade também e possibilidades de complementar ainda mais o projeto de extensão.

O terceiro foi o exercício "Corpo da emissão e corpo da escuta", realizado em duplas. Como preparo, nas aulas anteriores foi-nos solicitado levar, por escrito, o relato de alguma sensação boa ou ruim ou de algo que tivéssemos feito e que tivesse produzido algum efeito em alguém. O texto deveria estar decorado por nós, de forma direta, sem repetições de palavras. O objetivo era trabalhar o som, o timbre e a musicalidade das palavras emitidas, mais que seu significado, e verificar como isso estimulava impulsos de movimento e/ou movimentos em si.

Quem emitisse o som, o texto, deveria fazê-lo como se "tocasse o parceiro" ao mesmo tempo em que deveria atentar para o toque que as palavras faziam em seu próprio interior. De forma análoga a alguns dos exercícios propostos por Marcos Filho, começamos a criar movimentos através dos nossos próprios sons, internos; uma dança que nascia de dentro e que vinha à tona pelos estímulos contidos no nosso corpo.

O trabalho com a professora Carolina perpassou o exercício das qualidades de movimento e de sequências para ampliação do repertório corporal, com uso de rolamentos e atenção para a relação com o chão (bases da dança contemporânea), bem como noções de apoio e contrapeso. Buscou-se enfatizar a condição de pesquisador na 
qual o criador-intérprete deve se colocar, procurando descobrir novos caminhos para o movimento e para a corporificação das sensações e impulsos. Dentro do aspecto criativo, foram abordadas técnicas de contato e improvisação e de diálogos corporais. ${ }^{7}$

Em suas aulas também foram realizados seminários e rodas de leitura e discussão sobre diferentes estilos de dança e suas transformações até o surgimento da dança contemporânea, bem como a apreciação de vídeos de grupos de dança contemporânea.

Das sequências de movimentos praticadas com Carolina, do trabalho com as quedas e com a troca de peso, levo comigo, novamente, os fatores de percepção corporal e o estado de presença conquistado a cada momento, estar atenta para deixar o corpo vivenciar e conduzir o movimento e sua energia até o fim, a fim de que a ação seja vista de forma precisa e clara; novamente, a ativação de todas as partes do corpo para que a fluidez do movimento seja mantida. Um dos quatro fatores básicos das categorias de análise do movimento propostas por Rudolf $\operatorname{Laban}^{8}$, o fluxo recebeu atenção especial dos colaboradores que passaram pelo grupo naquele ano.

Destaco também os exercícios realizados a partir de saltos na primeira, segunda e terceira posições do balé, as impulsões proporcionadas pelo parceiro em trabalhos em dupla e a expressão de movimentos pelo estímulo aos sentimentos dos participantes.

Com a professora Juliana, vivenciamos a relação entre a preparação corporal e a expressão cênica do dançarino por meio de sequências coreografadas de alongamento e a atenção dada à relação entre o corpo e o espaço que o envolve. Outro fator foi a repetição de elementos como o apoio do corpo sobre os ísquios e sua relação com a atitude/postura da coluna vertebral; a atenção aos membros superiores e o desenho que estes realizavam no sala de ensaio. No trabalho de diálogo com o espaço, fizemos baterias de exercícios e jogos, como: improvisação com objetos imaginários; alteração de velocidade, do desenho da trajetória e dos planos dos movimentos. Para estimular nosso processo criativo, em duplas e trios, também entrelaçamos aleatoriamente os movimentos surgidos e trabalhados nas aulas com os professores André Magela e Carolina de Pinho.

A prática com estes colaboradores reforçou mais um dos princípios do projeto, apontado anteriormente: o de estimular as possibilidades individuais e seu aspecto 
autoral, guardando as especificidades e características de cada participante, no intuito de constituir uma "dança contemporânea com a cara do grupo". Reconheço nessa trajetória os princípios do Contato Improvisação quando seu criador, Steve Paxton, ao iniciar sua pesquisa, "estava interessado em descobrir como a improvisação em dança poderia facilitar a interação entre os corpos, as suas reações físicas e como proporcionar a participação igualitária das pessoas em um grupo". ${ }^{9}$

Também já mencionado, foi claramente percebido o contato com outros modos e estilos de dança e práticas, diferentes das oferecidas nas academias da cidade, estimulando a compreensão de que nem todo corpo dançante precisa se originar no balé clássico; antes, é preciso estar impulsionado pelo desejo de dançar, ser alimentado pela criatividade, pela disciplina para se acompanhar um grupo e pelo interesse em construir algo em conjunto.

Nesse sentido, quero reforçar três pontos que considero de grande importância para o meu aprendizado. O primeiro foi a participação de um portador de síndrome de down no grupo, o que nos fez aguçar o respeito pela diferença. Ainda que ele tivesse um tempo próprio, sua percepção e entendimento dos movimentos eram imediatos. Seu interesse em estar presente e sua alegria eram forças que impulsionaram o entrosamento de todos.

O segundo ponto foi a criação de uma nova cena coreográfica, Daquilo que me move, a partir de uma provocação que nos foi feita por Juliana, inspirada nos princípios de criação da coreógrafa Pina Bausch ${ }^{10}$. Ela nos perguntou sobre o que nos movia e sobre o que gostaríamos de falar por meio da dança? 


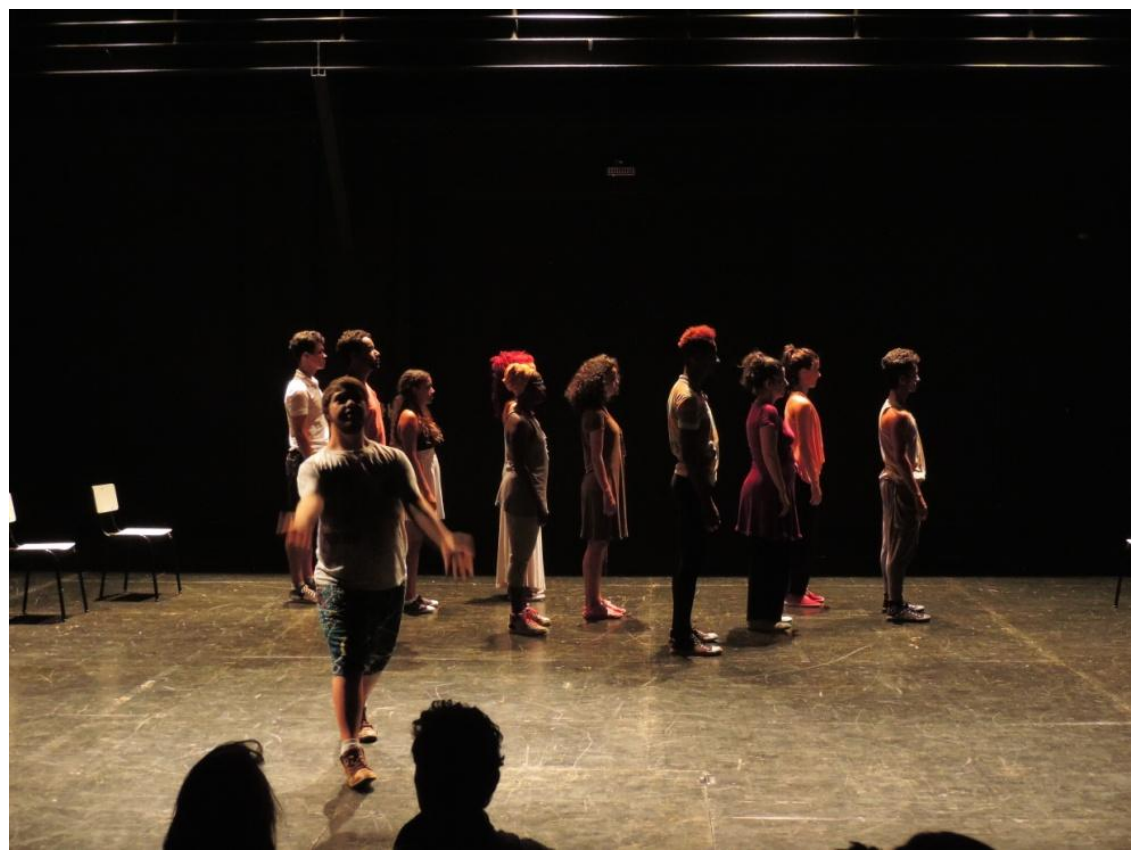

Figura 3. Foto: Gabriel Carneiro. Apresentação: Daquilo que me move. Dançarinos: Marcos Soares, William Francisco, Walfredo Junior, Priscila Silva, Raíssa Ventura, Lucimélia Romão, Raruza Kiara, Johnatan Seraphim, Lícya Benatti, Giselle Mara e Júnio de Carvalho.

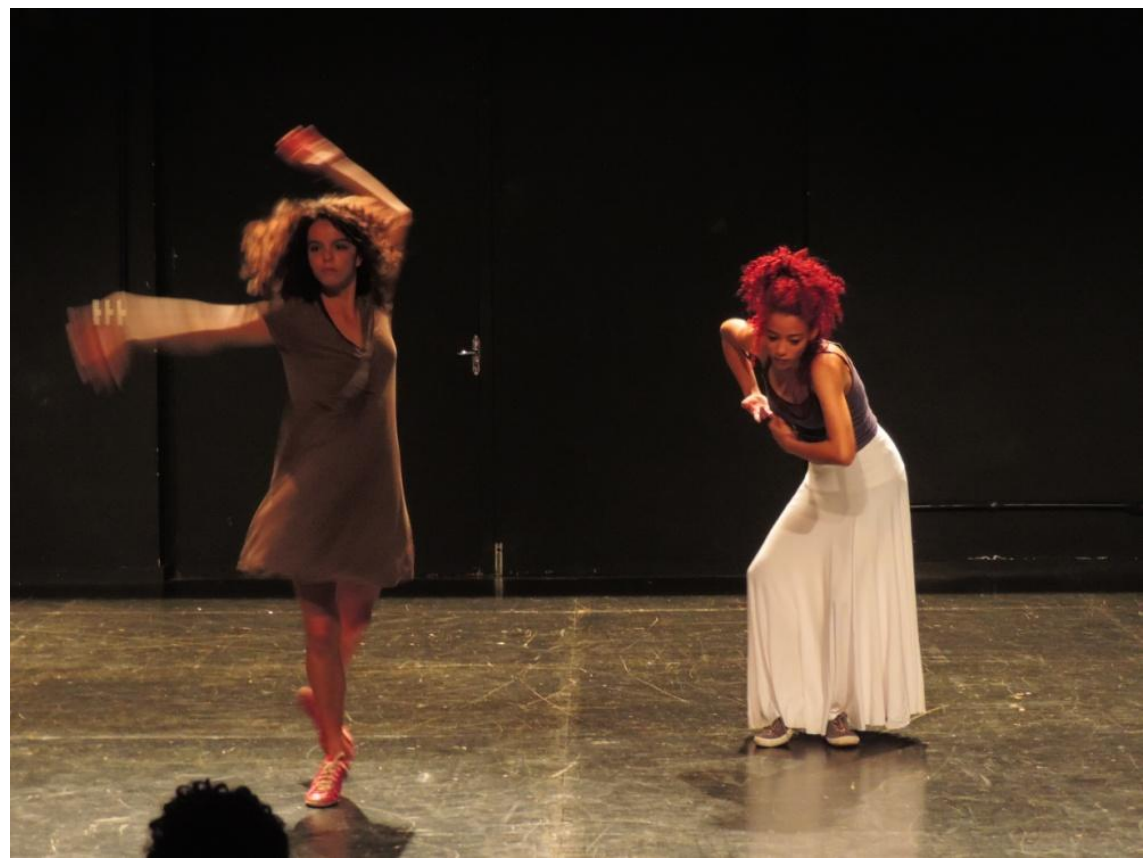

Figura 4. Foto: Gabriel Carneiro. Apresentação: Daquilo que me move. Dançarinas: Raíssa Ventura e Raruza Kiara. 
Essas perguntas permitiram que cada integrante explorasse não só sua subjetividade, como os estilos de dança com os quais já tinha tido contato. Assim, a coreografia final entrelaçou os movimentos individuais aos da dança moderna e contemporânea, com outros da cultura hip hop e passos de dança afro.

Antes das apresentações oficias do trabalho, fizemos ensaios abertos da cena pelos campi da UFSJ em São João Del Rei. Este procedimento fez com que percebêssemos e amadurecêssemos pequenos detalhes do trabalho, bem como nossa confiança como dançarinos. Desta vez, o retorno que tivemos foi o interesse de algumas pessoas do público em participar do edital de seleção para o ano de 2015.

Por fim, guardando a intenção de expandir o diálogo com a comunidade local, de incentivar a troca de experiência entre os envolvidos e sua interação por meio da dança e de alimentar a ponte extensão/ensino/pesquisa, em dois dias consecutivos ministramos uma aula de dança para os alunos da escola municipal João Pio, seguida da apresentação de Daquilo que me move e de uma sessão de improvisação aberta à participação de todos - dançarinos do grupo e alunos, professores, pais e funcionários da escola.

Agora, a troca de experiência aconteceu com crianças entre 3 e 10 anos de idade, deixando claro que o canal de comunicação estabelecido com elas foi o da criatividade e o do jogo, muito mais do que com uma ideia ou movimento preestabelecido. Sensação que se intensificou durante a apresentação da cena, quando percebi que elas murmuravam entre si ou riam diante do que assistiam, e quando se permitiram pular e dançar conosco. Mais do que em qualquer outro momento, compreendi a dança como um "modo de existir", como nos fala Klauss Vianna. ${ }^{11}$ 


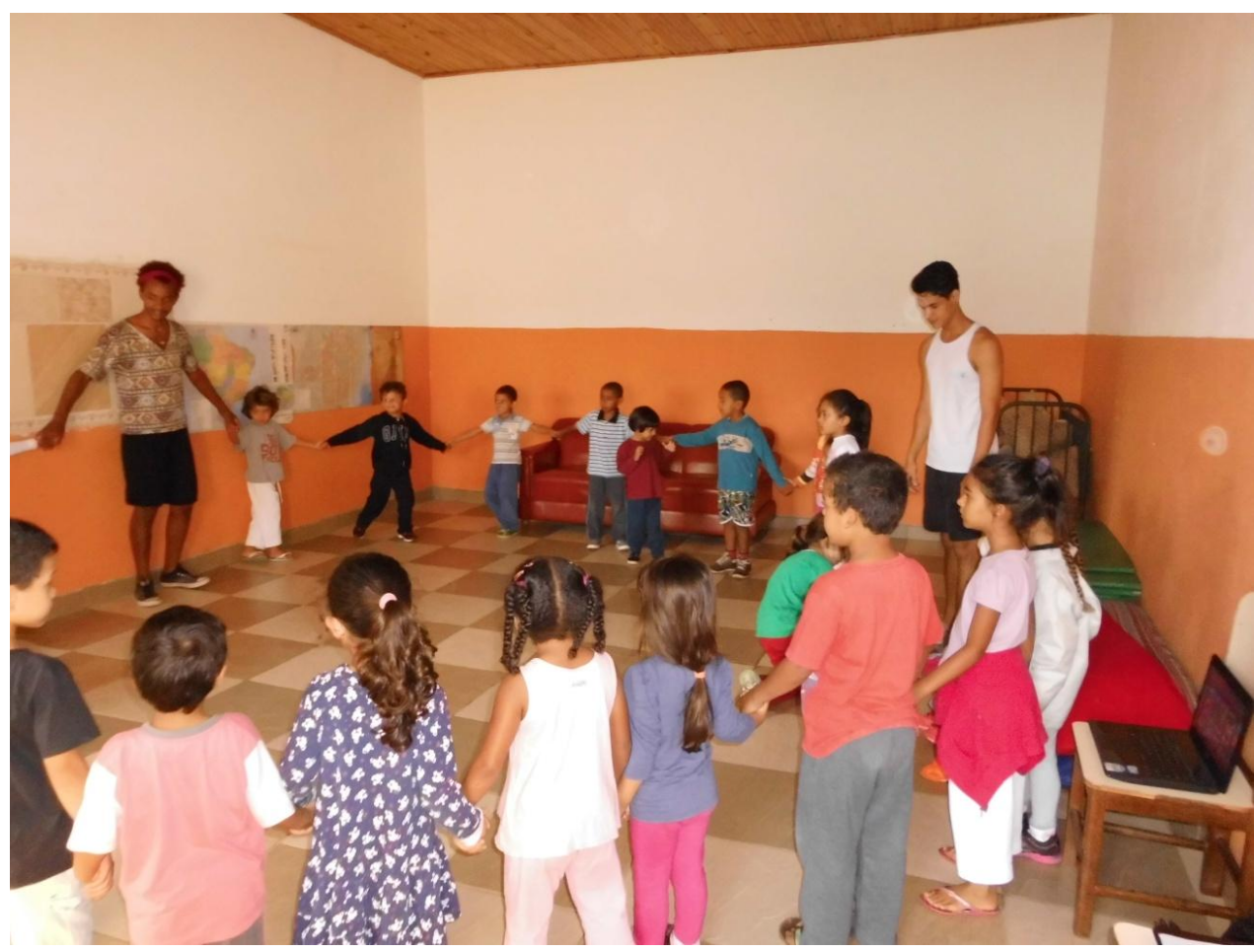

Figura 5. Foto: Juliana Monteiro. Membros do Murundum com alunos da João Pio.

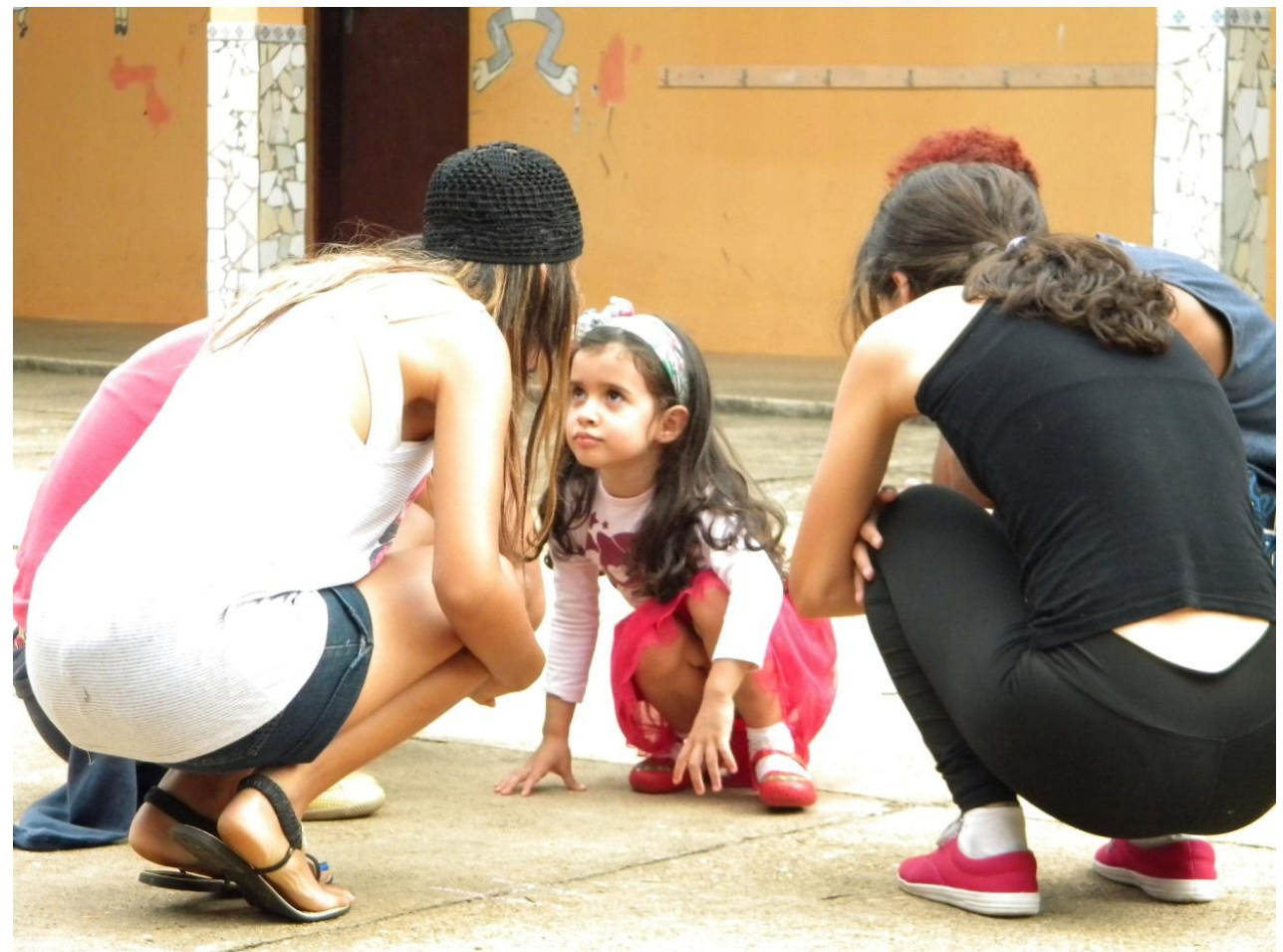

Figura 6. Foto: Juliana Monteiro. Membros do Murundum com alunos da João Pio. 


\section{Referências}

1. FABIÃO, Eleonora. Corpo cênico, estado cênico. Revista Contrapontos Eletrônica, Vol. 10 - n. 3 - p. 321-326 / set-dez 2010 . p. 322.

2. DELEUZE, Gilles, GUATARRI, Félix. Sobre rizoma. Disponível em: http://pt.wikipedia.org/wiki/Rizoma_\%28filosofia\%29. Acesso: 06 de março de 2015.

3. SIQUEIRA, Adilson. Busca e Retomada: Um processo para a construção da personagem pelo ator dançarino. Campinas: UNICAMP, 2000. Dissertação de Mestrado.

4. BOGART, Anne, LANDAU, Tina. The Viewpoints Book: A Practical Guide to Viewpoints and Composition. New York. Theatre Communication Group. 2005.

5. FILHO, Marcos. Relatório de trabalho. Acervo do Murundum Grupo de Dança Contemporânea da UFSJ, 2014. p. 1.

6. MAGELA, André. Relatório de trabalho. Acervo do Murundum Grupo de Dança Contemporânea da UFSJ, 2014. p. 6.

7. PINHO, Carolina de. Relatório de trabalho. Acervo do Murundum Grupo de Dança Contemporânea da UFSJ, 2014. p. 5.

8. LABAN, Rudolf von. Domínio do Movimento. São Paulo: Summus Editorial, 1978. 268p. Tradução: Anna Maria Barros de Vecchi e Maria Sílvia Mourão Netto.

9. LEITE, Fernanda Hübner de Carvalho. Contato improvisação (contact improvisation) - um diálogo em dança. Movimento Porto Alegre, v. 11, n. 2, p.89-110, maio/agosto de 2005. p. 90-91.

10. FERNANDES, Ciane. Pina Bausch e o Wuppertal Dança-teatro: Repetição e Transformação. São Paulo: Hucitec, 2000. 199p.

11. VIANNA, Klauss. A dança. São Paulo: Siciliano, 1990. 150p. 